\title{
More questions than answers as Canada's immunity task force releases initial results
}

— Cite as: CMAJ 2020 August 10;192:E933-4. doi: 10.1503/cmaj.1095887

Posted on cmajnews.com on July 24, 2020

nitial results of a study of blood donors have provided a first glimpse into how many Canadian adults have been infected with severe acute respiratory syndrome coronavirus 2 (SARSCoV-2), the virus that causes coronavirus disease 2019 (COVID-19).

The study, conducted by Canadian Blood Services and Canada's COVID-19 Immunity Task Force, found that fewer than $1 \%$ of 10000 samples tested positive for antibodies to the virus, indicating past infection with SARS-CoV-2.

These results are both good and bad news, says immunity task force co-chair Dr. Catherine Hankins.

The good news is that the public health measures taken by Canadians from staying home to wearing masks seem to have slowed spread of the virus, and Canada's case-fatality rate is likely much lower than initially thought.

Previously, based on the number of confirmed cases of COVID-19, "we had what appeared to be an extraordinarily high case-fatality rate that was around $8 \%$," Hankins explains.

However, the new findings would seem to confirm that there are several more infections in the community for every confirmed case of COVID-19. If one in 100 Canadians have been infected with the virus, Canada's true case-fatality rate is likely "quite a bit lower and more in line with what's being seen elsewhere... around $1 \%$," Hankins says.

The bad news is that a population seroprevalence of around $1 \%$ is a far cry from the $60 \%$ to $70 \%$ considered necessary for herd immunity.

"We've had a major pandemic come through this country and we're nowhere

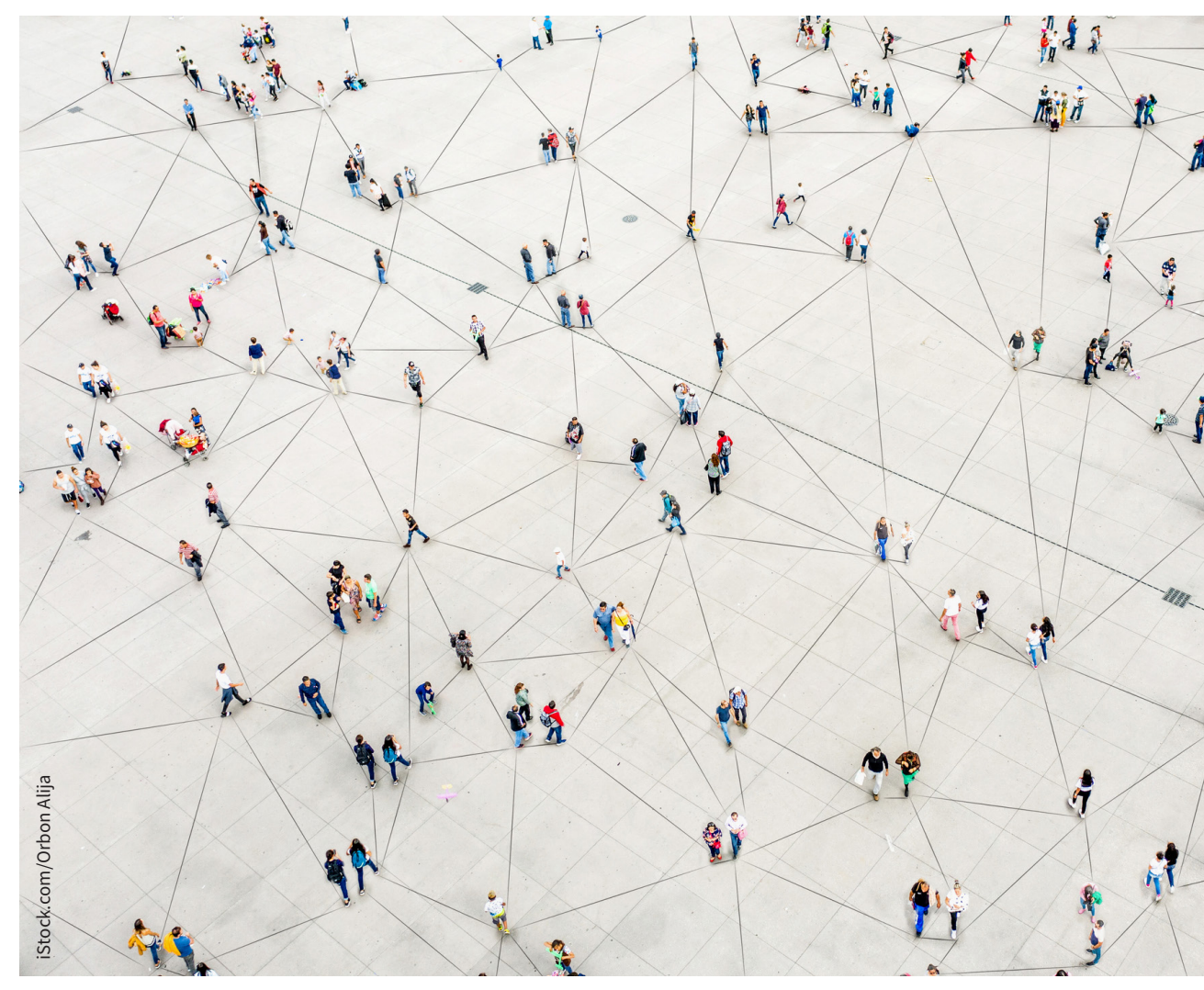

One in 100 Canadians may have been infected with SARS-CoV-2 in the first wave of the pandemic, according to the initial results of a study of blood donors.

near what scientists believe is required for herd immunity," Hankins says. "So, the vast majority of us remain susceptible to this."

This is not the end of the story, though. The present analysis included the results of testing 10000 blood samples for viral antibodies between May 9 and June 2, but Canadian Blood Services researchers are still completing their full analysis of 37800 samples collected during the study period.

Héma-Québec will release the results of a study of 7000 Quebec blood donors in the next few weeks, which Hankins says will be important for a complete national picture.

But blood donors are not necessarily representative of Canada's population since they tend to be young (aged 17-70), healthy, urban, and exclude people in the North, Hankins emphasized.

To get a clearer picture of national seroprevalence, the task force has teamed up with other research groups to round out the picture of the spread of SARS-CoV-2 in Canada. Initiatives in the pipeline include: 
- A study of specimens from pregnant women left over from rubella and syphilis testing. Hankins says pregnant women are generally representative of the reproductive age group.

- Adding testing for SARS-CoV-2 antibodies to the Canadian Longitudinal Study on Aging. Begun about 10 years ago, this national, long-term study of more than 50000 adults who were aged 45 to 85 at recruitment will follow participants until 2033 or death.

- A study of 15000 Indigenous people.

- A household study, representative of the entire country, conducted by Statistics Canada. This study will depend on validating the use of dried blood spots as specimens, which participants can collect themselves. Hankins says validation should be completed by the end of August, so the study may begin in September and wrap up by the end of the year.

The task force also plans to test three other groups for antibodies children, occupational groups such as health workers, and patients who have had COVID-19. Hankins notes that the last group will provide an opportunity to explore another of the task force's priority areas - understanding SARSCoV-2 immunity.

Researchers will examine the antibody levels of people who have had COVID-19 over time to see if they wane and if immune markers correlate with disease severity, the presence of lingering symptoms and organ damage after the acute infection has resolved.

When it comes to immunity, almost nothing is clearer now than when the task force was struck, except that the virus is more complicated than anyone expected, Hankins says. Questions persist about the role of antibodies in immunity and what that may mean for the prospects of a vaccine.

Recent studies have shown that patients with COVID-19 can generate an antibody response while still showing substantial viral loads and symptoms of the disease, and some people do not generate a measurable antibody response to infection, but still recover, so it's possible that other immune functions are involved.

Looking beyond seroprevalence and immunity studies, Canada's COVID-19 Immunity Task Force will also inform Canada's federal COVID-19 strategy, including identifying priority recipients when a successful vaccine becomes available and advising on when to lift pandemic restrictions.

The other task force members include co-chair Dr. David Naylor, who authored a report on Canada's handling of the SARS outbreak in 2003, Dr. Tim Evans of the School of Population and Global Health at McGill University, Canada's Chief Public Health Officer Dr. Theresa Tam, and Dr. Mona Nemer, chief science advisor to the Prime Minister, Minister of Science and Cabinet.

"We really want the science to drive the policy response," Hankins says. "We've been running as fast as we can. We're trying to be as nimble as possible and trying to make sure that we're aware of everything that's going on."

Terry Murray, Toronto, Ont. 